\title{
Componentes agronômicos do feijoeiro superprecoce BRS FC104 em diferentes arranjos espaciais e adubações fosfatadas
}

\author{
Cleber Morais Guimarães, Luis Fernando Stone, Pedro Marques da Silveira, Pedro Henrique Lopes \\ Sarmento
}

Embrapa Arroz e Feijão, Brasília, DF. E-mail: luis.stone@embrapa.br

\begin{abstract}
Resumo
A combinação adequada de espaçamento entrelinhas com o número de plantas por metro frente a diferentes condições edafoclimáticas é fundamental para a obtenção de maiores produtividades do feijoeiro. Este trabalho objetivou identificar o melhor arranjo espacial e dose de fosfato monoamônico (MAP) para maximizar o potencial produtivo da cultivar superprecoce de feijão-comum BRS FC104. Os experimentos foram conduzidos em Formosa, Cristalina, Santa Helena de Goiás e Santo Antônio de Goiás, em Goiás, no delineamento de blocos casualizados com parcelas subdivididas e quatro repetições. Nas parcelas, foram avaliadas cinco doses de MAP, 100, 150, 200, 250 e $300 \mathrm{~kg} \mathrm{ha}^{-1}$, e, nas subparcelas, cinco populações de plantas, 6, 8, 10, 12 e 14 plantas por metro. Foram conduzidos dois experimentos em cada localidade, com os devidos espaçamentos entrelinhas: 0,38 e 0,50 m. Dentre os componentes da produtividade, o número de vagens por planta foi o mais afetado pelo arranjo espacial de plantas, aumentando seu valor com o incremento no espaçamento entrelinhas e redução na população de plantas. A resposta da produtividade do feijoeiro ao espaçamento entrelinhas foi variável, dependendo da localidade e da dose de MAP. A plasticidade dos componentes da produtividade manteve a produtividade do feijoeiro estável frente às alterações na população de plantas, exceto em Santa Helena de Goiás, onde maior produtividade foi obtida com cerca de 14 plantas por metro. A adubação fosfatada incrementou a produtividade do feijoeiro em Santo Antônio de Goiás.
\end{abstract}

Palavras-chave: espaçamento entrelinhas; grãos por vagem; massa dos grãos; população de plantas; vagens por planta.

\section{Agronomic components of very early BRS FC104 common bean in different spatial arrangements and phosphate fertilizations}

\begin{abstract}
The adequate combination of row spacing with the number of plants per meter in front of different edaphoclimatic conditions is fundamental to obtain greater common bean yields. This work aimed to identify the best spatial arrangement and dose of monoammonium phosphate (MAP) to maximize the productive potential of very early BRS FC104 common bean cultivar. The experiments were conducted in Formosa, Cristalina, Santa Helena de Goiás, and Santo Antônio de Goiás, Goiás, in a randomized block design with split plots and four replications. In the plots, five doses of MAP, 100, 150, 200, 250, and $300 \mathrm{~kg}$ $\mathrm{ha}^{-1}$, and, in the subplots, five plant populations, 6, 8, 10, 12, and 14 plants per meter were evaluated. Two experiments were carried out in each locality, one at $0.38 \mathrm{~m}$ spacing and another at $0.50 \mathrm{~m}$ spacing. Among the grain yield components, the number of pods per plant was the most affected by the spatial arrangement of plants, increasing its value with the increase in row spacing and the reduction in plant population. The response of common bean yield to row spacing was variable, depending on the local and the dose of MAP. The plasticity of the grain yield components kept the common bean yield stable in relation to changes in the plant population, except in Santa Helena de Goiás, where greater grain yield was obtained with about 14 plants per meter. Phosphate fertilization increased common bean yield in Santo Antônio de Goiás.
\end{abstract}

Keywords: row spacing; grains per pod; grain weight; plant population; pods per plant. 


\section{Introdução}

A utilização correta do espaçamento e da densidade de semeadura na cultura do feijãocomum é prática cultural de baixo custo e de fácil adoção pelos agricultores. A distribuição adequada de plantas tem efeito sobre o controle de plantas daninhas e pode garantir uma utilização mais eficiente de alguns fatores de produção, como luz, água e nutrientes. Em situações contrárias, há sombreamento entre plantas e as raízes exploram a água e nutrientes no mesmo espaço do solo, aumentando o efeito da competição. De modo geral, o espaçamento recomendado é de 0,40 a 0,50 m entrelinhas, com 10 a 15 sementes por metro (ARAÚJO; CAMELO, 2015).

O número de vagens e o de grãos por planta são os componentes da produtividade mais afetados pela variação na densidade de plantas na linha de semeadura e no espaçamento entrelinhas. $O$ número de vagens é o primeiro componente da produtividade a ser definido na fase reprodutiva, sendo facilmente afetado pelo aumento da população de plantas, devido ao ambiente de competição. O número de grãos por vagem, por sua vez, é influenciado sobretudo pelas condições ambientais. Contudo, a competição por luz e fotoassimilados proporcionada pelo aumento da população de plantas pode ocasionar abortamento de flores e de grãos nas vagens, com redução do número de sementes produzidas. Já a massa de 100 grãos é o componente da produtividade menos influenciado pela população de plantas, por ser um caráter de herança qualitativa, pouco influenciado pelo ambiente e controlado por poucos genes (SANTOS et al., 2014).

As variações nos componentes da produtividade nem sempre estão relacionadas com a produtividade de grãos (ZILIO et al., 2011). A plasticidade dos componentes da produtividade frente a diferentes condições ambientais, devido a variações no espaçamento e população de plantas, pode facilitar a manutenção de um nível mais estável da produtividade de grãos, quando existir o efeito de compensação entre eles (SANTOS et al., 2014).

A cultivar superprecoce BRS FC104 foi lançada para atender à demanda dos agricultores por cultivares de feijão-comum mais precoces, a fim de aumentar a flexibilidade operacional nos sistemas de produção de feijão, por meio da antecipação ou retardamento da semeadura nas diferentes épocas e o cultivo em janelas curtas, permitindo maior eficiência do uso do solo, com a possibilidade de realização de até quatro cultivos não simultâneos por ano, caso não existam impedimentos sanitários e ou ambientais. Contudo, por ser uma cultivar superprecoce, ela pode demandar arranjo espacial diferenciado (GONZAGA, 2017).

A combinação adequada de espaçamento entrelinhas com o número de plantas por metro frente a diferentes condições edafoclimáticas é fundamental à obtenção de maiores produtividades de grãos. Adicionalmente, o manejo da fertilidade do solo é um aporte importante em sistemas de produção nos quais se pretende maximizar o potencial produtivo de uma cultivar.

Este trabalho teve por objetivo identificar o melhor arranjo espacial e dose de fosfato monoamônico para maximizar o potencial produtivo da cultivar superprecoce BRS FC104 em várias condições edafoclimáticas, em Goiás.

\section{Material e Métodos}

Os experimentos foram conduzidos em quatro fazendas: Sol, Pontinha, Santa Lúcia e Capivara, nos municípios de Formosa, Cristalina, Santa Helena de Goiás e Santo Antônio de Goiás, em Goiás, localizadas a 150 42' 28,80" de latitude Sul e 47 19' 35,65" de longitude Oeste, 16 47' $12,30^{\prime \prime}$ de latitude Sul e 470 48' 20,11" de longitude Oeste, 17ㅇ 41' 48,52" de latitude Sul e

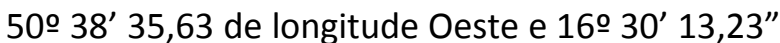
de latitude Sul e 49o 16' 54,73 de longitude Oeste, respectivamente. Os dados das análises químicas dos solos das áreas experimentais são apresentados na Tabela 1.

As semeaduras foram efetuadas em 05/05/2017, 12/05/2017, 23/05/2017 e 26/05/2017 em Formosa, Cristalina, Santa Helena de Goiás e Santo Antônio de Goiás, respectivamente, em parcelas de quatro fileiras, com cinco metros de comprimento. Adotou-se o delineamento experimental de blocos casualizados com parcelas subdivididas e quatro repetições. Nas parcelas, foram avaliadas cinco doses de fosfato monoamônico (MAP), 100, 150, 200, 250 e $300 \mathrm{~kg} \mathrm{ha}^{-1}$, aplicados na semeadura e, nas subparcelas, cinco populações de plantas, 6 , $8,10,12$ e 14 plantas por metro, estabelecidas aos sete dias após a emergência (estádio V3), após desbaste. Foram conduzidos dois experimentos em cada localidade, com espaçamentos entrelinhas de 0,38 e 0,50 m. Os experimentos de Formosa, Cristalina e Santo 
Antônio de Goiás receberam $80 \mathrm{~kg} \mathrm{ha}^{-1}$ de nitrogênio em cobertura e o de Santa Helena de Goiás, $120 \mathrm{~kg} \mathrm{ha}{ }^{-1}$, conforme o manejo agronômico das fazendas. Os demais tratos agronômicos foram aqueles usados rotineiramente nas propriedades agrícolas.

Tabela 1. Análises químicas dos solos das áreas experimentais das quatro fazendas em que foram conduzidos os experimentos: Sol, em Formosa, Pontinha, em Cristalina, Santa Lúcia, em Santa Helena de Goiás, e Capivara, em Santo Antônio de Goiás, no estado de Goiás

\begin{tabular}{lcccccccccccc}
\hline \multirow{2}{*}{ Local } & $\mathrm{pH}$ & $\mathrm{Ca}$ & $\mathrm{Mg}$ & $\mathrm{Al}$ & $\mathrm{P}$ & $\mathrm{K}$ & $\mathrm{Cu}$ & $\mathrm{Zn}$ & $\mathrm{Fe}$ & $\mathrm{Mn}$ & $\mathrm{M} . \mathrm{O}$. \\
& $\mathrm{H}_{2} \mathrm{O}$ & $----\mathrm{mmol}_{\mathrm{c}} \mathrm{dm}^{-3}$ & --- & ---------------- & $\mathrm{mg}^{-3}$ & $\mathrm{dm}^{-3}$ & -------------- & $\mathrm{g} \mathrm{kg}^{-1}$ \\
\hline Formosa & 7,0 & 47,0 & 14,4 & 0 & 83,0 & 452 & 2,1 & 11,6 & 17 & 18 & 44,6 \\
Cristalina & 5,7 & 43,4 & 10,4 & 0 & 23,5 & 203 & 2,9 & 8,4 & 31 & 21 & 11,3 \\
Santa Helena de Goiás & 5,7 & 54,8 & 14,8 & 0 & 12,0 & 137 & 1,5 & 4,7 & 14 & 32 & 35,1 \\
Santo Antônio de Goiás & 5,5 & 13,5 & 9,2 & 1 & 7,3 & 61 & 0,9 & 3,3 & 25 & 11 & 33,0 \\
\hline
\end{tabular}

Foram realizadas análises conjuntas por localidade, considerando-se os dois experimentos com diferentes espaçamentos. Avaliaram-se o número de vagens por planta, o número de grãos por vagem, a massa de 100 grãos e a produtividade de grãos. As médias referentes ao fator espaçamento entrelinhas foram comparadas pelo teste $t$ ao nível de $5 \%$ de probabilidade. A análise de regressão foi aplicada aos fatores população de plantas e dose de fosfato.

\section{Resultados e Discussão}

O número de vagens por planta foi afetado significativamente pelo espaçamento entrelinhas e pela população de plantas, em todas as localidades (Tabela 2). O espaçamento mais amplo propiciou maior número de vagens por planta (Tabela 3). No espaçamento de $0,50 \mathrm{~m}$ as plantas produziram $21,4 \%, 15,8 \%, 32,3 \%$ e $24,0 \%$ mais vagens que no espaçamento de 0,38 m em Formosa, Cristalina, Santa Helena de Goiás e Santo Antônio de Goiás, respectivamente.

O número de vagens por planta teve seu valor reduzido com o incremento da população de plantas de acordo com modelos polinomiais quadráticos (Figura 1). As plantas apresentaram, em média, 22,1; 20,9; 22,2 e 30,1 vagens na população de 6 plantas por metro, nas localidades de Formosa, Cristalina, Santo Antônio de Goiás e Santa Helena, respectivamente e 14,2; 12,$8 ; 12,9$ e 18,4 vagens com 14 plantas por metro, nas mesmas localidades, respectivamente. Embora não se tenha comparado estatisticamente as localidades, pelas curvas ajustadas observou-se que as plantas apresentaram tendência de carregamento de vagens semelhante nas três primeiras localidades e de maior número de vagens em Santa Helena de Goiás, em todas as populações de plantas. 
Tabela 2. Análise conjunta da variância do número de vagens por planta (NVP), número de grãos por vagem (NGV), massa de 100 grãos (M100) e produtividade (PROD) do feijoeiro nas fazendas Sol, em Formosa, Pontinha, em Cristalina, Santa Lúcia, em Santa Helena de Goiás, e Capivara, em Santo Antônio de Goiás, no estado de Goiás

\begin{tabular}{|c|c|c|c|c|c|c|c|c|c|}
\hline \multirow[t]{4}{*}{ Causa da variação } & \multirow[t]{4}{*}{ GL } & \multicolumn{8}{|c|}{ Quadrado médio } \\
\hline & & \multicolumn{4}{|c|}{ Formosa } & \multicolumn{4}{|c|}{ Cristalina } \\
\hline & & NVP & NGV & M100 & PROD & NVP & NGV & M100 & PROD \\
\hline & & \multicolumn{2}{|c|}{----- no ------ } & --- g --- & $\mathrm{Mg} \mathrm{ha}^{-1}$ & \multicolumn{2}{|c|}{ - - } & -- g -- & $\mathrm{Mg} \mathrm{ha}^{-1}$ \\
\hline Espaçamento (E) & 1 & $335,6 * *$ & $2,49 * *$ & $2,4 \mathrm{~ns}$ & $1,11 \mathrm{~ns}$ & $494,2 * *$ & $2,35^{*}$ & $3,2 \mathrm{~ns}$ & $0,89 \mathrm{~ns}$ \\
\hline \multicolumn{10}{|l|}{ Repetição dentro } \\
\hline exp. & 6 & $29,9 \mathrm{~ns}$ & $0,45 \mathrm{~ns}$ & $1,5 \mathrm{~ns}$ & $0,34 \mathrm{~ns}$ & $27,8 \mathrm{~ns}$ & $0,26 \mathrm{~ns}$ & $3,2 * *$ & $1,22 * *$ \\
\hline Dose de fosfato (D) & 4 & 44,3 ns & $0,31 \mathrm{~ns}$ & $1,3 \mathrm{~ns}$ & $0,08 \mathrm{~ns}$ & $56,2^{* *}$ & $1,22 \mathrm{~ns}$ & $11,5^{* *}$ & $0,52 \mathrm{~ns}$ \\
\hline$E \times D$ & 4 & $38,8 \mathrm{~ns}$ & $0,60 \mathrm{~ns}$ & $1,4 \mathrm{~ns}$ & $3,69 * *$ & $26,6 \mathrm{~ns}$ & $0,06 n s$ & $10,7^{* *}$ & $0,54 \mathrm{~ns}$ \\
\hline Erro a & 24 & 24,2 & 0,27 & 1,3 & 0,62 & 13,8 & 0,53 & 0,9 & 0,25 \\
\hline Popula & 4 & $408,5^{* *}$ & $0,51 \mathrm{~ns}$ & $3,7 * *$ & $0,41 \mathrm{~ns}$ & $449,4^{* *}$ & $0,18 n s$ & $3,3^{* *}$ & $0,35 \mathrm{~ns}$ \\
\hline$E \times P$ & 4 & $21,9 \mathrm{~ns}$ & $0,17 n s$ & $0,5 \mathrm{~ns}$ & ns & $6,5 \mathrm{~ns}$ & $0,29 \mathrm{~ns}$ & $1,0 \mathrm{~ns}$ & 4 ns \\
\hline$D \times P$ & 16 & $18,4 \mathrm{~ns}$ & $0,32 n s$ & $0,6 n s$ & $0,42 n s$ & $24,1 \mathrm{~ns}$ & $0,56 n s$ & $1,0 \mathrm{~ns}$ & $0,29 \mathrm{~ns}$ \\
\hline$E \times D \times P$ & 16 & $10,8 \mathrm{~ns}$ & $0,28 \mathrm{~ns}$ & $1,1 \mathrm{~ns}$ & $0,14 \mathrm{~ns}$ & $10,3 \mathrm{~ns}$ & $0,34 n s$ & $0,8 \mathrm{~ns}$ & $0,28 \mathrm{~ns}$ \\
\hline Erro b & 120 & 19,6 & 0,23 & 1,1 & 0,40 & 13,0 & 0,49 & 0,6 & 0,17 \\
\hline \multirow[t]{2}{*}{ CV (\%) } & & 24,9 & 11,1 & 4,7 & 22,0 & 22,5 & 14,3 & 3,6 & 13,57 \\
\hline & & \multicolumn{4}{|c|}{ Santa Helena de Goiás } & \multicolumn{4}{|c|}{ Santo Antônio de Goiás } \\
\hline Espaçamento (E) & 1 & $2000,3^{* *}$ & $0,03 n s$ & $8,8^{* *}$ & $0,85 n s$ & $632,2 * *$ & $4,23 * *$ & $1,4 \mathrm{~ns}$ & $1,02 \mathrm{~ns}$ \\
\hline \multicolumn{10}{|l|}{ Repetição dentro } \\
\hline exp. & 6 & $23,7 \mathrm{~ns}$ & $0,05 n s$ & $0,5 \mathrm{~ns}$ & $0,48 n s$ & $12,8 \mathrm{~ns}$ & $0,55^{*}$ & $4,2 \mathrm{~ns}$ & $1,09 * *$ \\
\hline Dose de fosfato (D) & 4 & $11,6 \mathrm{~ns}$ & $0,14 \mathrm{~ns}$ & $1,0 \mathrm{~ns}$ & $0,21 \mathrm{~ns}$ & $51,8^{* *}$ & $0,63^{*}$ & 4,0ns & $5,22 * *$ \\
\hline$E \times D$ & 4 & $31,0 \mathrm{~ns}$ & $0,92 n s$ & $0,9 \mathrm{~ns}$ & $0,35 \mathrm{~ns}$ & $7,9 \mathrm{~ns}$ & $0,24 n s$ & $5,4 \mathrm{~ns}$ & $0,97^{*}$ \\
\hline Erro a & 24 & 27,4 & 0,32 & 1,0 & 0,33 & 9,8 & 0,19 & 3,4 & 0,32 \\
\hline População (P) & 4 & $935,1 * *$ & $0,30 \mathrm{~ns}$ & $14,2^{* *}$ & $1,23 * *$ & $572,7 * *$ & $0,36^{*}$ & 4,0ns & $0,40 \mathrm{~ns}$ \\
\hline$E \times P$ & 4 & $54,2 \mathrm{~ns}$ & $0,50 \mathrm{~ns}$ & $2,0 \mathrm{~ns}$ & $0,19 \mathrm{~ns}$ & $2,5 \mathrm{~ns}$ & $0,09 \mathrm{~ns}$ & $5,0 \mathrm{~ns}$ & $0,16 \mathrm{~ns}$ \\
\hline$D \times P$ & 16 & $22,8 \mathrm{~ns}$ & $0,30 \mathrm{~ns}$ & $1,0 \mathrm{~ns}$ & $0,28 \mathrm{~ns}$ & $5,2 \mathrm{~ns}$ & $0,09 \mathrm{~ns}$ & $3,7 \mathrm{~ns}$ & $0,14 \mathrm{~ns}$ \\
\hline$E \times D \times P$ & 16 & $29,9 \mathrm{~ns}$ & $0,52 \mathrm{~ns}$ & $0,7 \mathrm{~ns}$ & $0,32 \mathrm{~ns}$ & $6,0 \mathrm{~ns}$ & $0,15 n s$ & $4,2 \mathrm{~ns}$ & $0,16 \mathrm{~ns}$ \\
\hline Erro b & 120 & 34,7 & 0,28 & 1,1 & 0,26 & 9,4 & 0,13 & 3,7 & 0,22 \\
\hline CV (\%) & & 26,0 & 11,2 & 5,0 & 15,5 & 18,2 & 7,4 & 8,1 & 13,1 \\
\hline
\end{tabular}

ns - F não significativo a $5 \%, *$ - F significativo a $5 \%$ e ** - F significativo a $1 \%$

O número de vagens por planta é o primeiro componente da produtividade a ser definido na fase reprodutiva, sendo mais facilmente afetado pelo aumento da população, devido ao ambiente de competição. Geralmente há redução desse componente em função do incremento de plantas por hectare, como constataram Santos et al. (2014). O ajuste do número de vagens por planta, entre outros fatores, ocorre de acordo com a disponibilidade de fotoassimilados. O maior abortamento de vagens em maiores populações de plantas e em espaçamentos mais estreitos pode ser reflexo da incapacidade da planta em suprir adequadamente as vagens vingadas, pois elevados índices de área foliar no estádio de formação das vagens, causados pelo adensamento excessivo das plantas, promovem o sombreamento mútuo das folhas, reduzindo a fotossíntese líquida (SILVA et al., 2012). 
Tabela 3. Número de vagens por planta (NVP), número de grãos por vagem (NGV), massa de 100 grãos (M100) e produtividade (PROD) do feijoeiro nos espaçamentos de $0,38 \mathrm{~m}$ e $0,50 \mathrm{~m}$ entrelinhas, nas fazendas Sol, em Formosa, Pontinha, em Cristalina, Santa Lúcia, em Santa Helena de Goiás, e Capivara, em Santo Antônio de Goiás, no estado de Goiás

\begin{tabular}{ccccc}
\hline Espaçamento $(\mathrm{m})$ & \multicolumn{5}{c}{ Formosa } \\
\cline { 2 - 5 } & $\mathrm{NVP}(\mathrm{n}$ - $)$ & NGV (no) & M100 (g) & PROD (Mg ha $\left.{ }^{-1}\right)$ \\
\hline 0,38 & $16,5 \mathrm{~b}$ & $4,4 \mathrm{a}$ & $22,37 \mathrm{a}$ & $2,95 \mathrm{a}$ \\
0,50 & $19,1 \mathrm{a}$ & $4,2 \mathrm{~b}$ & $22,15 \mathrm{a}$ & $2,80 \mathrm{a}$ \\
\hline \multicolumn{5}{c}{ Cristalina } \\
\hline 0,38 & $14,5 \mathrm{~b}$ & $4,8 \mathrm{~b}$ & $22,42 \mathrm{a}$ & $2,95 \mathrm{a}$ \\
0,50 & $17,6 \mathrm{a}$ & $5,0 \mathrm{a}$ & $22,67 \mathrm{a}$ & $3,08 \mathrm{a}$ \\
\hline \multicolumn{5}{c}{ Santa Helena de Goiás } \\
\hline 0,38 & $19,5 \mathrm{~b}$ & $4,7 \mathrm{a}$ & $20,91 \mathrm{~b}$ & $3,38 \mathrm{a}$ \\
0,50 & $25,8 \mathrm{a}$ & $4,7 \mathrm{a}$ & $21,33 \mathrm{a}$ & $3,25 \mathrm{a}$ \\
\hline \multicolumn{5}{c}{ Santo Antônio de Goiás } \\
\hline 0,38 & $15,0 \mathrm{~b}$ & $4,6 \mathrm{~b}$ & $23,63 \mathrm{a}$ & $3,55 \mathrm{a}$ \\
0,50 & $18,6 \mathrm{a}$ & $4,9 a$ & $23,79 \mathrm{a}$ & $3,70 \mathrm{a}$ \\
\hline
\end{tabular}

Médias seguidas pela mesma letra na coluna não diferem significativamente ao nível de $5 \%$ pelo teste $t$.

Figura 1. Número de vagens por planta de feijoeiro em função da população de plantas

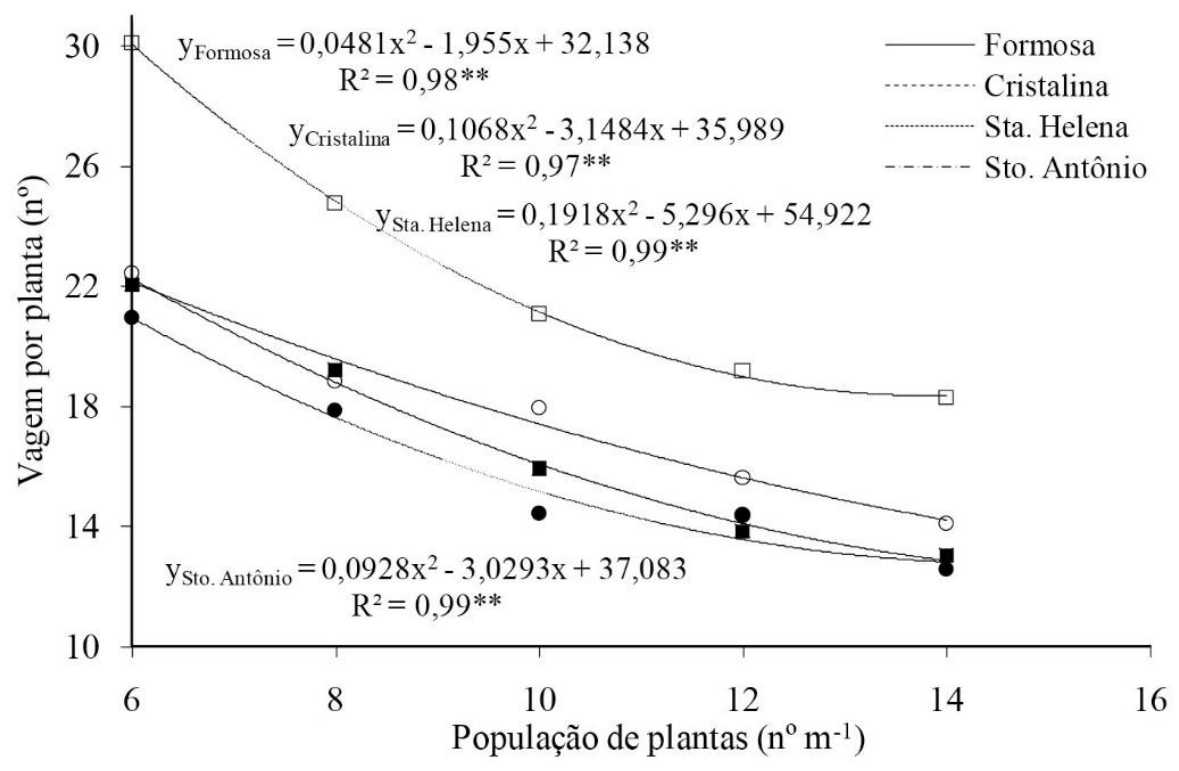

Em Cristalina e Santo Antônio de Goiás, as doses de fosfato monoamônico afetaram significativamente o número de vagens por planta (Tabela 2). Em Santo Antônio de Goiás, esse componente da produtividade aumentou com as doses do fertilizante segundo um modelo polinomial quadrático $\left(y=-0,0001 x^{2}+0,0572 x+\right.$ 10,$4086 ; R^{2}=0,96 *$ ), registrando-se um máximo de 18,6 vagens por planta com a aplicação de 286 $\mathrm{kg} \mathrm{ha}^{-1}$ do fertilizante. Nessa localidade, o teor de fósforo no solo era o menor entre as áreas experimentais (Tabela 1). Em Cristalina, embora com tendência de aumento com as doses de MAP, os dados não se ajustaram significativamente a nenhum modelo matemático. Oliveira et al. (2014) constataram que a adubação fosfatada favoreceu o desenvolvimento das plantas de feijoeiro, aumentando o número de vagens por planta. Nascente et al. (2014a), em Santo Antônio de Goiás, observaram resposta quadrática do número de vagens por $\mathrm{m}^{2}$ a doses de fertilizante fosfatado.

O número de grãos por vagem foi influenciado significativamente pelo espaçamento entrelinhas em todas as localidades, exceto em Santa Helena de Goiás (Tabela 2), aumentando com o incremento do 
espaçamento em Cristalina e Santo Antônio de Goiás (Tabela 3). O aumento do espaçamento aumenta a relação área por planta, o que, consequentemente, aumenta a exposição das plantas à luz e incrementa sua fotossintetização. A redução no espaçamento, por sua vez, faz com que as folhas inferiores não recebam quantidade adequada de luz e, como consequência, as vagens da parte inferior da planta não se desenvolvem por falta de fotoassimilados, em razão da prioridade de deslocamento de carboidratos pela constituição das unidades fonte-dreno em feijoeiro. A falta de carboidrato, além de corroborar com a má formação dos grãos, pode ocasionar o seu aborto, diminuindo o número de grãos por vagem (SANTOS et al., 2014). Em Formosa, o número de grãos por vagem foi maior no espaçamento de $0,38 \mathrm{~m}$. Como havia nutrientes suficientes para atender a demanda das plantas, uma vez que a fertilidade do solo era maior nessa localidade, a competição por carboidratos foi menor, o que pode ter contribuído para não haver redução do número de grãos por vagem com o espaçamento mais estreito.

As doses de fosfato não afetaram significativamente o número de grãos nas vagens da BRS FC104 nas localidades de Formosa, Cristalina e Santa Helena de Goiás (Tabela 2). Em Santo Antônio de Goiás, o efeito das doses de MAP sobre esse componente foi significativo, contudo, embora com tendência de aumento com o incremento das doses de MAP, os dados não se ajustaram significativamente a um modelo matemático.

O número de grãos por vagem não foi influenciado significativamente pela população de plantas em nenhuma das localidades, exceto em Santo Antônio de Goiás (Tabela 2) onde, entretanto, não se observou ajustamento significativo de um modelo matemático. Santos et al. (2014) também não constataram efeito da população de plantas nesse componente da produtividade. Diferentemente do que ocorre com o número de vagens por planta, o número de grãos por vagem é mais influenciado pelas condições ambientais que pela população de plantas (SANTOS et al., 2014).

A massa de 100 grãos não foi influenciada significativamente pelo espaçamento entrelinhas, de maneira isolada, em nenhuma das localidades, exceto em Santa Helena de Goiás (Tabela 2), em que o espaçamento de $0,50 \mathrm{~m}$ condicionou maior massa, 21,33 g, contra 20,91 g observada no espaçamento de 0,38 m (Tabela 3). Essas foram as menores massas de 100 grãos observadas entre as localidades experimentais. Em Cristalina, a interação entre espaçamento entrelinhas e dose de MAP foi significativa para a massa de 100 grãos (Tabela 2), que apresentou maiores valores no espaçamento de $0,50 \mathrm{~m}$, nas doses de $200 \mathrm{e}$ $300 \mathrm{~kg} \mathrm{ha}^{-1}$ de MAP. Nas demais doses, os espaçamentos não diferiram significativamente. Em ambos os espaçamentos, o efeito das doses de MAP nesse componente não pode ser explicado por um modelo matemático.

Babaeian et al. (2012) também observaram incremento na massa de 100 grãos do feijoeiro com o aumento do espaçamento entrelinhas. Zilio et al. (2011) relataram que a compensação entre o número de vagens por planta e a massa dos grãos, em função da alteração no espaçamento entrelinhas, é comum no feijoeiro, graças à plasticidade da espécie. Ribeiro et al. (2014) observaram que a massa dos grãos apresentou correlação negativa com o número de grãos por planta e com o número de grãos por vagem e Fernandes et al. (2015) encontraram correlação negativa entre número de vagens por planta e massa de 100 grãos, mostrando a existência de grande plasticidade entre os componentes da produtividade de grãos do feijoeiro, resultando em capacidade de compensação.

A massa de 100 grãos foi afetada significativamente pelas doses de fertilizantes apenas em Cristalina (Tabela 2), aumentando segundo modelo polinomial quadrático $(\mathrm{y}=$ $\left.0,00006 x^{2}+0,02570 x+20,11175 ; R^{2}=0,97^{* *}\right)$ até a dose de $214 \mathrm{~kg} \mathrm{ha}^{-1}$, quando a massa de 100 grãos foi de $22,86 \mathrm{~g}$.

A população de plantas afetou significativamente a massa de 100 grãos em todas as localidades, exceto em Santo Antônio de Goiás (Tabela 2). Contudo, ajuste significativo ocorreu apenas em Cristalina, onde a massa de 100 grãos diminuiu com 0 incremento da população de plantas segundo modelo polinomial quadrático $\left(y=0,03 x^{2}-0,84 x+27,63 ; R^{2}=\right.$ $0,99 * *)$, com o valor mínimo de $22,36 \mathrm{~g}$ por 100 grãos observado com 12 plantas por metro.

Lopes (2011), para a cultura do feijãocaupi, também constatou que menores populações de plantas propiciaram maiores massas dos grãos. Por outro lado, outros autores obtiveram ganho de massa de grãos com o aumento da população de plantas (ARRUDA et al., 2009; MATOS FILHO et al., 2009). Santos et al. 
(2014) relataram que os efeitos da população de plantas sobre a massa de 100 grãos são muito variáveis e bastante influenciados pela cultivar.

Embora o espaçamento entrelinhas tenha afetado os componentes da produtividade, especialmente o número de vagens por planta e o de grãos por vagem, ele, isoladamente, não afetou significativamente a produtividade do feijoeiro. Contudo, em Formosa e Santo Antônio de Goiás, a interação de espaçamento entrelinhas e dose de MAP foi significativa para produtividade (Tabela 2). Em Formosa, constatou-se que, nas doses de 150 e $200 \mathrm{~kg} \mathrm{ha}^{-1}$, o espaçamento de $0,38 \mathrm{~m}$ propiciou maiores produtividades; nas demais doses os espaçamentos não diferiram significativamente. A adubação fosfatada não afetou significativamente a produtividade do feijoeiro em nenhum dos espaçamentos. Em Santo Antônio de Goiás, observou-se que, no espaçamento de $0,50 \mathrm{~m}$, a produtividade do feijoeiro respondeu às doses de fertilizante, aumentando segundo um modelo polinomial quadrático até a dose máxima testada, alcançando 4,08 Mg ha ${ }^{-1}$ (Figura 2). No espaçamento de $0,38 \mathrm{~m}$, embora com tendência de resposta crescente da produtividade até a dose de $228 \mathrm{~kg} \mathrm{ha}^{-1}$, o ajuste não foi significativo. Como discutido anteriormente, nessa localidade a adubação fosfatada incrementou o número de vagens por planta e o de grãos por vagem e o teor de fósforo no solo era o menor entre as áreas experimentais (Tabela 1). Nessa localidade, na maior dose de MAP, o espaçamento de 0,50 m propiciou maior produtividade.

Figura 2. Produtividade de grãos do feijoeiro em função de doses do fosfato monoamônico (MAP), em Santo Antônio de Goiás.

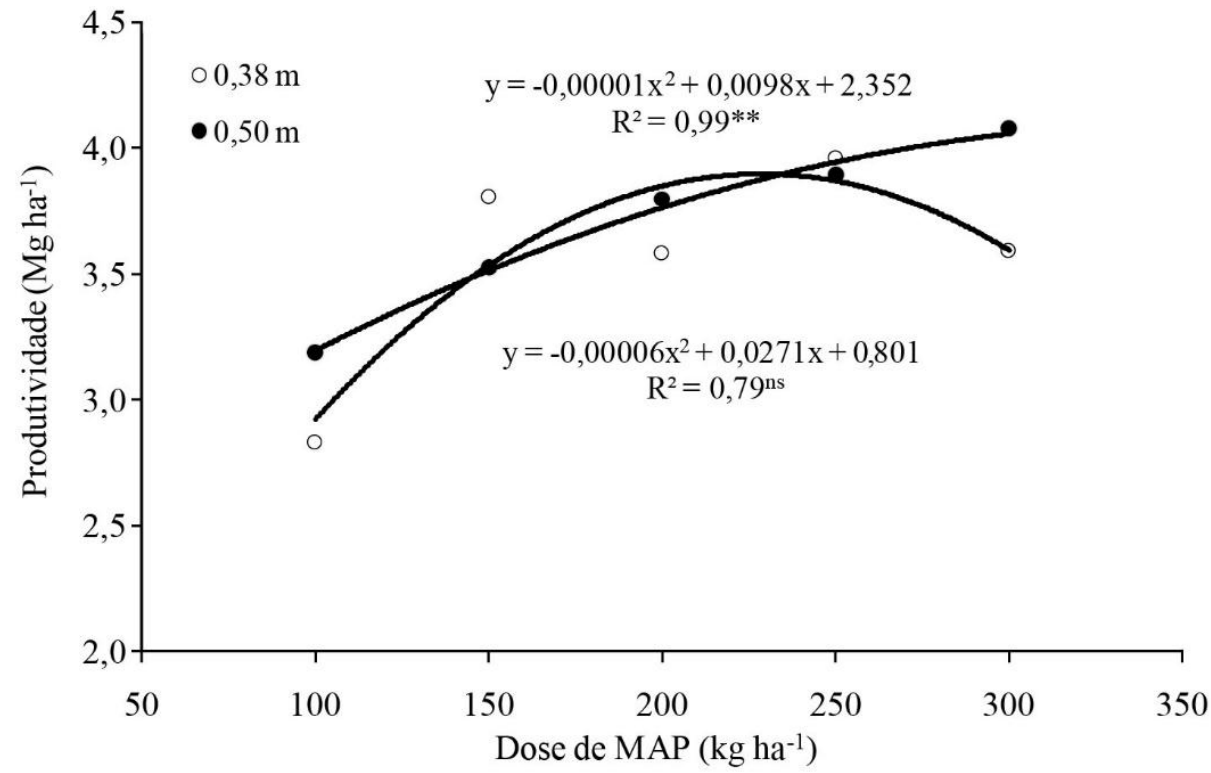

Valderrama et al. (2009), Viana et al. (2011) e Oliveira et al. (2014) relataram incrementos na produtividade do feijoeiro com o aumento de doses de fósforo. Nascente et al. (2014b) constataram esse aumento com a aplicação de fosfato monoamônico.

A produtividade do feijoeiro não foi influenciada significativamente pelo efeito isolado da população de plantas em nenhuma das localidades, exceto em Santa Helena de Goiás (Tabela 2), em que respondeu segundo modelo polinomial quadrático $\left(y=-0,0069 x^{2}+0,1919 x+\right.$ 2,1534; $\left.R^{2}=0,95^{* *}\right)$, atingindo o máximo de 3,49 $\mathrm{Mg} \mathrm{ha}^{-1} \mathrm{com} 13,9$ plantas por metro.
Variações nos componentes da produtividade nem sempre estão relacionadas com variação na produtividade de grãos (ZILIO et al., 2011). A plasticidade desses componentes pode manter a produtividade do feijoeiro estável frente a alterações no espaçamento entrelinhas e população de plantas, quando existir o efeito de compensação entre eles (SANTOS et al., 2014). Ziviani et al. (2009) não constataram efeito da população de plantas na produtividade de grãos da cultivar de feijoeiro Carioca, o mesmo resultado encontrado por Santos et al. (2014), para três cultivares de feijoeiro. Em maiores espaçamentos entrelinhas, cultivares de feijoeiro 
de hábito prostrado e indeterminado podem emitir novas ramificações, aproveitando melhor os espaços vazios e produzirem tanto quanto em espaçamentos mais reduzidos (ZIVIANI et al., 2009).

\section{Conclusões}

O número de vagens por planta é o componente da produtividade do feijoeiro mais afetado pelo arranjo espacial de plantas, aumentando seu valor com o incremento no espaçamento entrelinhas e redução na população de plantas.

A resposta da produtividade do feijoeiro ao espaçamento entrelinhas é variável, dependendo da localidade e da dose do fosfato monoamônico.

A plasticidade dos componentes da produtividade mantém a produtividade do feijoeiro estável frente a alterações na população de plantas, exceto em Santa Helena de Goiás, onde maior produtividade é obtida com cerca de 14 plantas por metro.

A adubação fosfatada incrementa a produtividade do feijoeiro em Santo Antônio de Goiás.

\section{Referências}

ARAÚJO, G. A. A.; CAMELO, G. N. Preparo do solo e plantio. In: CARNEIRO, J. E.; PAULA JÚNIOR, T. J. de; BORÉM, A. (Ed.). Feijão: do plantio à colheita. Viçosa: UFV, 2015. p. 115-144.

ARRUDA, K. R.; SMIDERLE, O. J.; VILARINHO, A. A. Uniformidade de sementes de genótipos de feijão caupi cultivados em dois ambientes no Estado de Roraima. Revista Agro@mbiente Online, v.3, n.2, p. 122-127, 2009.

http://dx.doi.org/10.18227/1982-

8470ragro.v3i2.280

BABAEIAN, M.; JAVAHERI, M.; ASGHARZADE, A. Effect of row spacing and sowing date on yield and yield components of common bean (Phaseolus vulgaris L.). African Journal of Microbiology Research, v.6, n.20, p. 4340-4343, 2012. https://doi.org/10.5897/AJMR11.1311

FERNANDES, R. C.; GUERRA, J. G. M.; ARAÚJO, A. P. Desempenho de cultivares de feijoeiro-comum em sistema orgânico de produção. Pesquisa Agropecuária Brasileira, v.50, n.9, p. 797-806, 2015. http://dx.doi.org/10.1590/S0100$\underline{204 \times 2015000900008}$
GONZAGA, A. C. de O. Densidade de plantas e fornecimento de nitrogênio para a cultivar de feijão-comum superprecoce BRS FC104. 2017. 91 f. Dissertação (Mestrado em Agronomia) Universidade Federal de Uberlândia, Minas Gerais, 2017.

LOPES, F. C. L. Estudo de densidade de semeadura e espaçamento de linhas sobre o rendimento do feijão Vigna unguiculata em condição do Agreste pernambucano. 2011. 73 f. Dissertação (Mestrado em Processamento e Armazenamento de Produtos Agrícolas) Universidade Federal do Ceará, Fortaleza, 2011.

MATOS FILHO, C. H. A.; GOMES, R. L. F.; ROCHA, M. M.; FREIRE FILHO, F. R.; LOPES, A. C. Potencial produtivo de progênies de feijão-caupi com arquitetura ereta de planta. Ciência Rural, v.39, n.2, p. 348-354, 2009.

http://dx.doi.org/10.1590/S0103-

84782009000200006

NASCENTE, A. S.; COBUCCI, T.; SOUSA, D. M. G. de; LIMA, D. P. Adubação fosfatada no sulco e foliar afetando a produtividade de grãos do feijoeiro comum. Semina: Ciências Agrárias, v.35, n.3, p. 1231-1240, 2014a.

http://dx.doi.org/10.5433/1679-

0359.2014v35n3p1231

NASCENTE, A. S.; COBUCCI, T.; SOUSA, D. M. G. de; LIMA, D. de P. Produtividade do feijoeiro comum afetada por fontes de fósforo com ou sem cálcio. Revista de Ciências Agrárias, v.57, n.2, p. $180-185,2014 b$.

http://dx.doi.org/10.4322/rca.2014.012

OLIVEIRA, T. C.; SILVA, J.; SANTOS, M. M. dos; CANCELLIER, E. L.; FIDELIS, R. R. Desempenho agronômico de cultivares de feijão em função da adubação fosfatada no sul do Estado do Tocantins. Revista Caatinga, v.27, n.1, p. 50-59, 2014.

RIBEIRO, N. D.; DOMINGUES, L. S.; ZEMOLIN, A. E. $M$. Avaliação dos componentes da produtividade de grãos em feijão de grãos especiais. Científica, v.42, n.2, p. 178-186, 2014.

https://doi.org/10.15361/1984-

$\underline{5529.2014 v 42 \mathrm{n} 2 \mathrm{p} 178-186}$

SANTOS, M. G. P.; CARVALHO, A. J.; DAVID, A. M. S. S.; AMARO, H. T. R.; VIEIRA, N. M. B.; SOUZA, V. 
B.; CARNEIRO, J. E. S. Densidades de semeadura e safras de cultivo no desempenho produtivo de cultivares de feijoeiro-comum. Semina: Ciências Agrárias, v.35, n.5, p. 2309-2324, 2014.

http://dx.doi.org/10.5433/1679-

$\underline{0359.2014 v 35 n 5 p 2309}$

SILVA, R. R.; CARIOTTO, S.; MALAGI, G.; MARCHESE, J. A. Análise de crescimento em feijoeiro cultivado sob diferentes densidades de semeadura. Scientia Agraria, v.13, n.2, p. 41-51, 2012. http://dx.doi.org/10.5380/rsa.v13i2.40883

VALDERRAMA, M.; BUZETTI, S.; BENETT, C. G. S.; ANDREOTTI, M.; ARF, O.; SÁ, M. E. Fontes e doses de nitrogênio e fósforo em feijoeiro no sistema plantio direto. Pesquisa Agropecuária Tropical, v.39, n.3, p. 191-196, 2009.

VIANA, T. O.; VIEIRA, N. M. B.; MOREIRA, G. B. L.; BATISTA, R. O.; CARVALHO, S. J. P. de; RODRIGUES, H. F. F. Adubação do feijoeiro cultivado no norte de Minas Gerais com nitrogênio e fósforo. Revista Ceres, v.58, n.1, p. 115-120, 2011. http://dx.doi.org/10.1590/S0034$\underline{737 \times 2011000100017}$

ZILIO, M.; COELHO, C. M. M.; SOUZA, C. A.; SANTOS, J. C. P.; MIQUELLUTI, D. J. Contribuição dos componentes de rendimento na produtividade de genótipos crioulos de feijão (Phaseolus vulgaris L.). Revista Ciência Agronômica, v.42, n.2, p. 429-438, 2011.

http://dx.doi.org/10.1590/S1806$\underline{66902011000200024}$

ZIVIANI, A. C.; RIBEIRO JÚNIOR, W. Q.; RAMOS, M. L. G.; BARBOSA, M. A. A. F.; CORDEIRO, A.; FRANÇA, L. V. Arranjos espaciais de feijoeiro de portes contrastantes e seus efeitos na produtividade e cobertura vegetativa. Bioscience Journal, v.25, n.2, p. 1-9, 2009. 